\title{
“TODO ES SEGÚN EL DOLOR CON QUE SE MIRA" Apuntes Para un Debate en Torno a la Construcción de Conocimiento en Procesos de Lucha
}

\author{
http://dx.doi.org/10.21527/2176-6622.2020.54.21-31
}

Recebido em: 7/9/2020

Aceito em: 19/9/2020

Manuel E. Gándara Carballido

Miembro de la Red de Apoyo por la Justicia y la Paz y del Instituto Joaquín Herrera Flores. Profesor en el Programa Oficial de Máster en "Derechos Humanos, Interculturalidad y Desarrollo" de la Universidad Pablo de Olavide de Sevilla (España). Licenciado en Filosofía por la Universidad Santa Rosa de Lima (Venezuela), con Maestría en Filosofía de la Práctica por la Universidad Católica Andrés Bello (Venezuela) y Máster en Derechos Humanos, Interculturalidad y Desarrollo por la Universidad Pablo de Olavide (España). Doctor en Derechos Humanos y Desarrollo por la Universidad Pablo de Olavide (España). Desde el segundo semestre de 2019 es Profesor Visitante del Programa de Postgrado en Derecho de la Universidad Federal de Río de Janeiro (Brasil). http://lattes.cnpq.br/6727241177196505. https://orcid.org/00000002-5308-0345. manuelgandara68@gmail.com

\section{RESUMEN}

El texto desarrolla algunas reflexiones a propósito del quehacer teórico y la construcción de conocimiento que se produce en el marco de las luchas por transformar la sociedad en clave emancipadora. Para ello se acude a los aportes del pensamiento crítico, particularmente del pensamiento crítico en derechos humanos. Se destaca el lugar de las víctimas como opción no solo ética y política, sino también como lugar epistémico, desafiando los enquistamientos en que cierto ejercicio académico puede incurrir.

Palabras-clave: Derechos humanos. Pensamiento crítico. Teoría crítica. Teórico.

\section{"TUDO DEPENDE DA DOR COM A QUAL VOCÊ OLHA". NOTAS PARA UM DEBATE SOBRE A CONSTRUÇÃO DO CONHECIMENTO EM PROCESSOS DE LUTA}

\section{RESUMO}

O texto desenvolve algumas reflexões sobre o fazer teórico e a construção do conhecimento que ocorre no marco das lutas para transformar a sociedade na perspectiva emancipatória. Para isso, são utilizadas as contribuições do pensamento crítico, em particular do pensamento crítico sobre os direitos humanos. O lugar das vítimas é destacado como uma opção não apenas ética e política, mas também como um lugar epistêmico, desafiando os entrincheiramentos em que um determinado exercício acadêmico pode incorrer.

Palavras-chave: Direitos humanos. Pensamento crítico. Teoria crítica.

\section{SUMÁRIO}

1 Introducción. 2 Nuestro punto de partida, la opción ético-política por los empobrecidos. 3 El qué y el para qué de las teorías. 4 La labor de los teóricos. 5 Referencias. 


\section{INTRODUCCIÓN}

La frase de Mario Benedetti con que hemos titulado este texto da cuenta de nuestro punto de partida, que no es otro que la opción ético-política a favor de aquellas personas y sectores de la sociedad que han sido sometidos a relaciones de subordinación, exclusión, dominación e incluso exterminio.

En nuestro esfuerzo por comprender la realidad para tratar de intervenir en ella, hemos de pretender el mayor rigor metodológico y constante honestidad con lo real, pero ello no lo disfrazamos de una supuesta e imposible neutralidad. No somos neutrales, nadie lo es, aunque algunos se escuden en dicha pretensión para escurrir el debate y el sometimiento a crítica de sus presupuestos y posicionamientos. Como no hay neutralidad, la mejor manera de tender a cierta búsqueda de objetividad es someterse al examen intersubjetivo de nuestras apuestas. Nosotros optamos por las víctimas.

\section{NUESTRO PUNTO DE PARTIDA, LA OPCIÓN ÉTICO-POLÍTICA POR LOS EMPOBRECIDOS}

Decía Theodor Adorno, uno de los principales representantes de la teoría crítica de la Escuela de Frankfurt, que "la necesidad de prestar voz al sufrimiento es condición de toda verdad." Con ello fijaba posición y alertaba contra toda pretendida "neutralidad" cómplice por parte del quehacer científico. Esa misma opción ética debe seguir alentando el quehacer del pensamiento crítico hoy en día.

Frente a la supuesta neutralidad axiológica de la ciencia, defendida por la teoría tradicional, es necesario reconocer que toda ciencia es movida por un interés, y que negarlo puede no ser más que una forma de enmascaramiento ideológico. ${ }^{2}$

Sabiéndolo o no, todo pensamiento se posiciona de una determinada manera en el marco del conflicto de intereses que atraviesa nuestro mundo; por ello, resulta necesario una perspectiva crítica que se haga cargo de la forma en que se avalan o se confrontan las diferentes opciones ético-políticas desde las que se comprende e interviene en la realidad. ${ }^{3}$ Como bien afirma Boaventura de Sousa Santos, "la teoría crítica siempre ha tenido como presupuesto suyo la pregunta: ¿de qué lado estamos'? y la respectiva respuesta." ${ }^{4}$ Así, a una teoría crítica no le resulta indiferente el lugar y la perspectiva desde la que se piensa y se intenta intervenir en la realidad.

Toda teoría, aunque sea de manera implícita, supone una serie de decisiones previas que responden a una determinada forma de pensamiento y le sirven de base, condicionando sus apuestas epistemológicas y metodológicas. ${ }^{5}$ Por ello, es peligrosa la postura ingenua que desconoce la significación que tiene el conocimiento; los postulados teóricos surgen en un determinado contexto histórico y responden a él, cumpliendo la función de dificultar o impulsar determinados proyectos sociales. ${ }^{6}$ En palabras de Hugo Zemelman:

El movimiento de la realidad socio-histórica y su estrecha vinculación con la práctica social obliga a un constante esfuerzo por descifrar los límites (que pueden ser teóricos, ideológicos o axiológicos) en cuyo espacio reviste un significado particular el fenómeno que se quiere estudiar.

Estos límites expresan la opción social desde la cual se construye el conocimiento; implican, por lo tanto, una forma de entender a la realidad, pero especialmente de cómo y para qué construirla en una dirección determinada. Lo que decimos reviste un significado relevante cuando observamos que los parámetros que en general

\footnotetext{
ADORNO, Teodor, Dialéctica negativa. Madrid: Akal, 2005. p. 28.

2 Cfr. CORTINA, Adela. La Escuela de Fráncfort. Crítica y Utopía. Madrid: Síntesis, 2008. p. 48-49.

3 Cfr. ROMERO CUEVAS, José. "Ellacuría: una teoría crítica desde América Latina". In: Revista Internacional de Filosofía Política, Madrid: UAM-Uned, n. 32, p. 7, 2008.

4 SANTOS, Boaventura. Crítica de la razón indolente. Contra el desperdicio de la experiencia. Bilbao: Desclée de Brouwer, 2003. p. 286.

5 Cfr. MEDICCI, Alejandro. "El arraigo de Anteo: las lecciones políticas de Joaquín Herrera Flores". In: REDHES, San Luis Potosí: Universidad Autónoma San Luis Potosí, n. 4, p. 17, jul./dic. 2010.

6 Cfr. ZEMELMAN, Hugo. Debate sobre la situación actual de las ciencias sociales, p. 5. Disponible en: http://www.archivochile.com/ldeas Autores/zemelmanh/zemelman0007.pdf. Disponible en: 19 sept. 2012. Ver también SENENT DE FRUTOS, J. Notas sobre una Teoría Crítica de los Derechos Humanos. In: Anuario Iberoamericano de derechos humanos 2001-2002. Río de Janeiro, 2002. p. 411.
} 
se imponen, sin mediar muchas veces conciencia alguna del investigador, son los que conforman el poder, en cuyos parámetros se pretende conferir a los fenómenos el estatus de reales; con el agregado de establecer su identidad como única y excluyente de otras posibles visiones de los mismos. ${ }^{7}$

La teoría crítica asume, pues, conscientemente una serie de opciones, de posicionamientos éticos y políticos frente a la realidad; y los hace explícitos, con lo que se abre al discernimiento, el juicio y la crítica como forma de validación intersubjetiva.

Pero, ha de entenderse que la nuestra no es solo una opción ética y política; es, también, un posicionamiento hermenéutico. Se asume que la perspectiva de las víctimas, de aquellos a quienes se les niega las condiciones necesarias para vivir con dignidad, es el lugar hermenéutico por excelencia para comprender los procesos sociales en curso. ${ }^{8}$

Entendiendo que "la neutralización epistemológica del pasado siempre ha sido la contraparte de la neutralización social y política de las 'clases peligrosas'", ${ }^{9}$ se opta por una aproximación al proceso socio-histórico que permita visibilizar y reconocer la perspectiva de quienes en dicha dinámica han sido marginados, excluidos e invisibilizados desde las narrativas oficiales y los saberes hegemónicos. Como bien dice Enrique Dussel:

El método crítico consiste en colocarse en el espacio político de los pobres, las víctimas, y desde allí llevar a cabo la crítica de las patologías del Estado. Desde ese lugar epistemológicos - el de las víctimas, las del sur del planeta, los oprimidos, los excluidos, los nuevos movimientos populares, los pueblos ancestrales colonizados por la Modernidad, por el capitalismo que se globaliza, todo lo cual queda expresado en redes mundiales altermundistas - será desde donde tendremos que ir efectuando la crítica de todo el sistema de las categorías de la filosofía política burguesa. ${ }^{10}$

Pero, insistimos, asumir este posicionamiento no pretende solo ofrecer una oportunidad de visibilización a las narrativas que han sido marginalizadas del debate público, lo que ya sería un acto de justicia y una ampliación de las perspectivas de debate que aseguraría un mayor rigor metodológico; más allá de eso, se afirma que esta perspectiva de las víctimas del sistema social, de quienes han cargado con la peor parte, permite una mejor comprensión de dicho sistema que la perspectiva de quienes se ven beneficiados por él.

Se trata de poner en marcha procesos de lectura y transformación de la realidad que identificando la injusticia del sistema y enfrentándola, permitan que todos y todas puedan disfrutar de condiciones de vida digna; y ésa es una tarea imposible si se mira la realidad desde los intereses de quienes se ven favorecidos por la estructural injusticia en que vive nuestras sociedades. Desde las víctimas, desde los empobrecidos, desde quienes han sido excluidos, es posible plantearse dinámicas de inclusión universal que reviertan los procesos de marginación. Es en este sentido que se afirma que "la universalidad de los derechos humanos sólo podrá ser efectiva si se implica y afecta prioritariamente con la versión sobrante de la humanidad: las víctimas." ${ }^{11}$

Al fin y al cabo, se trata de pensar y vivir desde una opción por las víctimas, en contra de las dinámicas de victimización. ${ }^{12}$ La búsqueda de una sociedad sin víctimas, que haya logrado erradicar toda forma de victimización actúa como horizonte utópico. ${ }^{13}$ Así, pues, la opción ética por los desfavorecidos permite la formulación de un proyecto de dignidad que alcanza a todos.

Sin embargo, consideramos pertinente la advertencia sobre el riesgo que subyace a esta opción ética de convertirse en una forma de paternalismo, que luchando por los pobres termine desplazándoles del protagonismo que les corresponde en su propio proceso de liberación. El sujeto principal de la praxis liberadora

\footnotetext{
ZEMELMAN, Hugo, Debate sobre la situación actual de las ciencias sociales, p. 3. Disponible en: http://www.archivochile.com/Ideas_Autores/zemelmanh/zemelman0007.pdf. Disponible en: 19 sept. 2012.

8 Cfr. ETXEBERRÍA, Javier. Prólogo. In: ASIER, Martínez de Bringas. Exclusión y victimización. El grito de los derechos humanos en la globalización. Bilbao: Alberdania, 2004. p. 13.

9 SANTOS, Boaventura, La globalización del derecho. Los nuevos caminos de la regulación y la emancipación. Bogotá: Instituto Latinoamericano de Servicios Legales Alternativos - Ilsa, 1991. p. 235.

${ }^{10}$ DUSSEL, Enrique, Política de la liberación. Historia Mundial y Crítica. Madrid: Trotta, 2007. p. 552.

${ }^{11}$ MARTÍNEZ DE BRINGAS, Asier, Exclusión y victimización. El grito de los derechos humanos en la globalización. Bilbao: Alberdania, 2004. p. 19.

${ }^{12}$ Cfr. DUSSEL, Enrique. Ética de la Liberación en la Edad de la Globalización y de la Exclusión. Madrid: Trotta, 2006. p. 417.

${ }^{13}$ Cfr. SÁNCHEZ RUBIO, David. Filosofía, derecho y liberación en América Latina. Bilbao: Desclée de Brouwer, 1999. p. 204.
} 
son las propias víctimas que conscientes de su situación emprenden procesos de organización, articulación y movilización como colectivo para lograr transformar aquellas realidades que les oprimen; ${ }^{14}$ así, la labor solidaria de quienes se sumen a esta lucha no puede pretender sustituirles en el proceso de comprensión de la problemática que les aqueja ni en la búsqueda de alternativas superadoras. ${ }^{15}$

Es necesario, pues, repensar la historia y los derechos humanos a partir del encuentro con quienes son negados en su humanidad, en diálogo con ellos y ellas. Desde la perspectiva de las víctimas del sistema, de sus necesidades e intereses, resulta urgente confrontar toda narrativa que, puesta al servicio de la conservación del status quo, impida su potencial transformador. ${ }^{16}$

Afirmamos que esta opción es necesaria para recuperar el potencial emancipador del quehacer histórico en pro de los derechos humanos. Frente a la cooptación de la narrativa de derechos humanos en función de los intereses de los grupos de poder, resulta urgente repensar estos derechos desde los procesos de lucha que son llevados adelante por los sectores excluidos, sus prácticas de resistencia. ${ }^{17}$

Frente a ciertos discursos sobre derechos, que más que neutrales son neutralizadores de las alternativas de lucha que buscan enfrentar la injusta distribución de los bienes y las oportunidades de vida digna, es preciso, siguiendo a Ignacio Ellacuría, atender al "para quién", al "para qué" y al "desde dónde" de los derechos humanos. ${ }^{18}$

\section{EL QUÉ Y EL PARA QUÉ DE LAS TEORÍAS}

Es conocida la formulación de Horkheimer según la cual la teoría tradicional se entiende como una acumulación de saber utilizable para la caracterización de los hechos, de forma tal que la explicación teórica, según esta perspectiva, se entendería como el acto de subsumir la percepción que se tiene de "situación objetiva" en el marco de ese saber estructurado por conceptos. ${ }^{19}$ Queremos destacar de esta forma de concebir la teoría, cómo la misma da por supuesta la separación entre la realidad que ha de ser explicada y el saber teórico del que se ha de disponer para explicar dicha realidad. El saber se entiende como un cúmulo de proposiciones estructuradas jerárquicamente de forma tal que de unas se van deduciendo las otras, siendo más perfecta una teoría en la medida en que es menos el número de primeros principios en comparación con las consecuencias que de ellos se derivan. ${ }^{20}$

El hiato entre realidad y saber teórico llega a ser entendido por la teoría tradicional como una garantía de la universalidad de sus postulados, al no estar circunscritos a una circunstancias específicas. Ante esta pretensión de validez universal de la teoría, Hinkelammert afirma que "Ia única forma de lograr esta omnisciencia es tautologizándola, solo así puede presentarse válida para todos los tiempos y lugares, aunque no tenga ningún potencial explicativo." ${ }^{21}$ Igualmente, desde la perspectiva de la teoría tradicional se asume que la explicación de la realidad que realiza el teórico ha de ser neutral, limitándose a subordinar a la estructura conceptual del saber los hechos que "encuentra" en la realidad, sin que en dicho proceso interfieran sus necesidades ni intereses particulares.

El problema con la concepción tradicional de teoría es que pretende describir la realidad dejando de lado los procesos históricos, los contextos de gestación de los fenómenos y de la comprensión de esos fenómenos; la teoría tradicional, y la ciencia que desde ella se desarrolla, desconoce lo socio-histórico; además,

\footnotetext{
${ }^{14}$ Cfr. ROSILLO, Alejandro. Fundamentación de los derechos humanos desde la Filosofía de la liberación. Mimeo, [201-?]. p. 12-13.

${ }^{15}$ Cfr. MARTíNEZ De BRINGAS, Asier, Exclusión y victimización. El grito de los derechos humanos en la globalización. Bilbao: Alberdania, 2004. p. 136.

${ }^{16}$ Cfr. Rosillo, Alejandro. Fundamentación de los derechos humanos desde la Filosofía de la liberación. Mimeo, [201-?]. p. 8.

17 GUILLÉN, Maryluz. "Concepción hegemónica de los derechos humanos: la lucha de los Yukpas por su tierra". In: Diálogo de saberes, n. 4. Disponible en: http://dialogosaberes.ubv.edu.ve/index.php?option=com_content\&view=article\&id=158:concepcion-hegemonica-de-los-derechos-humanos-la-lucha-de-los-yukpas-por-su-tierra\&catid=19:sumario-revista-no-4\&Itemid=13. Acceso en: 19 sept. 2012.

${ }^{18}$ Cfr. ELLACURía, Ignacio. Historización de los derechos humanos desde los pueblos oprimidos y las mayorías populares. In: Escritos Filosóficos, San Salvador: UCA Editores, Tomo III, 2001.

${ }^{19}$ Cfr. HORKHEIMER, Max. Teoría tradicional y teoría crítica. In: Teoría Crítica. Buenos Aires: Amorrortu, 1974. p. 223.

${ }^{20}$ Cfr. HORKHEIMER, Max. Teoría tradicional y teoría crítica. In: Teoría Crítica. Buenos Aires: Amorrortu, 1974. p. 222.

${ }^{21}$ HINKELAMMERT, Franz, Claves de un pensamiento crítico. Entrevista a Franz Hinkelammert por Henry Mora. In: HERRERA FLORES, Joaquín (ed.). El vuelo de Anteo. Derechos Humanos y Crítica de la razón Liberal. Joaquín Herrera Flores (ed.). Bilbao: Desclée de Brouwer, 2000. p. 295.
} 
supone una única razón o racionalidad, y una sola forma de conocimiento válido. Como expone Arriscado Nunes, la teoría se ha entendido generalmente en una relación de oposición, o al menos de tensión, con las instancias corporalizadas, territorializadas y localizadas del mundo concreto: la práctica, la experiencia, la investigación empírica, la política, etc. ${ }^{22}$

Con tales presupuestos, la teoría tradicional olvida lo que de forma sintética formuló Robert Cox: "Theory is always for someone and for some purpose," ${ }^{23}$ corriendo el riesgo de que arropada en una retórica abstracta sirva, como frecuentemente ocurre, para justificar prácticas de todo tipo. Por ello, un autor como Helio Gallardo, plantea que si bien es cierto que la confiabilidad de una teoría (así como su provisoriedad) dependerá del cumplimiento o no de las predicciones que realiza, su "verdad" se encuentra siempre en función del posicionamiento inicial que asume y de las operaciones eficaces que dicho posicionamiento genera en términos de conocimiento. Pero las "teorías", afirma este autor "no son verdaderas en el sentido de que "las cosas son así como la teoría las presenta', o en lenguaje académico, no son 'ónticamente' así, sino que son 'interpretadas de esa manera' desde una determinada, fundada y disciplinar perspectiva humana." ${ }^{24}$ De tal manera que, en el sentido del pragmatismo epistemológico, una teoría no pretende decir "lo que las cosas son", sino que busca ser útil para incidir en la realidad desde la producción de conocimiento. ${ }^{25}$ Por ello, los instrumentos teóricos deben estar siempre expuestos a la crítica, sometidos al discernimiento autocrítico "desde el movimiento que la produce y al que esa teoría compromete." ${ }^{26}$

Frente a los postulados de la teoría tradicional, el pensamiento crítico enfrenta su tarea intentando ser honesta con los hechos con que se encuentra en la realidad, respetando así la dureza de lo real, sin ocultar ni ocultarse a sí misma lo que la investigación le presenta como dato, y ello lo hace precisamente por su interés en comprender para transformar, pues no confunde objetividad con neutralidad. Por el contrario, las teorías críticas reconocen y hacen explícitas las condiciones de su producción, que le condicionan, y también sus opciones políticas, éticas e ideológicas. Optan por una sociedad justa, que atienda a las necesidades e intereses de los empobrecidos, excluidos y discriminados, haciendo su aporte para que todos y todas puedan gozar de condiciones que les permitan definir y desarrollar sus proyectos vitales.

Los teóricos críticos no reniegan de la función política de la labor que realizan. Entienden su quehacer siempre en el marco del campo de fuerzas que constituyen las tramas sociales, sabiendo que su producción responde a la configuración sociohistórica de la que surge, bien para fortalecerla, bien para combatirla. Por ello, es necesario permanecer atentos a la función efectiva que en los procesos sociales cumple una determinada teoría, preguntándonos si contribuye o no a hacer posible horizontes diferentes a los propuestos desde el pensamiento único y unificador; es necesario atender a si las teorías abren o no la posibilidad de otros imaginarios que no se limiten a repetir lo dado como completo y clausurado.

Es necesario, pues, que las teorías ayuden a encontrar nuevas vías para la acción social, que posibiliten el descubrimiento de nuevos medios de lucha a quienes apuestan por procesos emancipadores. ${ }^{27}$ Nuevamente según Herrera Flores, "Ia teoría nunca debe conformarse, adaptarse sin más a la tiranía de los hechos, sino, con palabras del gran poeta uruguayo Mario Benedetti, esforzarse por construir de nuevo utopías aún más intrépidas que las fracasadas." 28

\footnotetext{
${ }^{22}$ Cfr. NUNES, João. "Transição paradigmática, pós-modernismo crítico e teoria social”. In: Oficina do CES, Coimbra: CES-Feuc, n. 81, p. 10, 1996.

23 "La teoría es siempre para alguien y para algún propósito" (traducción propia). COX, Robert. Theory Talk, n. 37. Disponible en: http://www. theory-talks.org/2010/03/theory-talk-37.html). Acceso en: 10 oct. 2012.

${ }^{24}$ GALLARDO, Helio. Teoría crítica y derechos humanos. Una lectura latinoamericana. In: FUNDACIÓN JUAN VIVES SURIA; DEFENSORIA DEL PUEBLO VENEZUELA. Los derechos humanos desde el enfoque crítico. Caracas: Fundación Juan Vives Suria, 2011. p. 47.

25 GALLARDO, Helio. Siglo XXI. Producir un mundo. Toronto, Canadá: Harlequin, 2006. p. 351.

${ }^{26}$ GALLARDO, Helio. Derechos humanos como movimiento social. Colombia: Ediciones Desde Abajo, 2006. p. 16.

${ }^{27}$ Cfr. HERRERA FLORES, Joaquín. "De la rueda y el freno. El camino hacia la democracia en Georg Lukacs y Rosa Luxemburg". In: Crítica Jurídica. Revista Latinoamericana de Política, Filosofía y Derecho, Facultades do Brasil, n. 18, p. 259-281, 2001.

${ }^{28}$ HERRERA FLORES, Joaquín. "¿Crisis de la ideología o ideología de la crisis? Respuestas neoconservadoras”. In: Crítica Jurídica. Revista Latinoamericana de Política, Filosofía y Derecho, Instituto de Investigaciones Jurídicas, Universidad Nacional Autónoma de México, n. 13, p. 129, 1993.
} 
Estos desafíos, como decimos, se le hacen patentes al intelectual crítico como consecuencia de su opción por los oprimidos. Esta misma opción le obliga a permanecer en constante atención de su posicionamiento frente a los procesos sociales en los que participa y en lo que ineludiblemente su producción juega un papel, lo quiera él o no. Su propia posición en las tramas sociales y en las relaciones de poder y la función que puede o no cumplir su teoría, le obligan a "una constante vigilancia epistemológica y política sobre sí mismo, para evitar que su ayuda se vuelva vana o incluso contraproducente." 29 Ello se hace particularmente urgente en sociedades marcadas por relaciones asimétricas de poder y configuradas por procesos de exclusión, subordinación y explotación, pues las mismas tienen la capacidad para incorporar y ajustar a sus lógicas incluso las producciones teóricas generadas con pretensiones emancipadoras. Es necesario pues, asumir explícitamente un posicionamiento contra-hegemónico en el quehacer teórico para evitar que las inercias sociales terminen devorando y metabolizando, en función de las prácticas establecidas, las producciones críticas que se proponen desarrollar un sentido crítico. ${ }^{30}$

Es constitutivo de la teoría crítica el asumir su labor en el marco de las prácticas sociales. Por ello, Helio Gallardo insiste en que las teorías, todas ellas, son constitutivas de la representación y reproducción de la realidad, a la vez que han sido constituidas por ella y para ella...

Las "teorías", todas, forman parte de lo real-social y humano. Surgen desde la realidad social y contribuyen de diversas formas con la reproducción del orden que las requiere y legitima. Las teorías son políticamente funcionales o disfuncionales...

Las "teorías" no son algo exterior a los conflictos de la sociedad que las produce y requiere. De hecho, ninguna producción humana es "exterior" a las tramas sociales en las que se gestan y ninguna está "por encima" de ellas. $^{31}$

Han de evitarse, por tanto, los discursos absolutizadores, caracterizados por la pretensión de estar constituidos de forma separada e independiente del contexto en que son producidos. Por el contrario, para el pensamiento crítico, la praxis y los intereses sociales que tienen lugar en dichos contextos configuran el punto de vista a partir del cual "se constituye el objeto de conocimiento", 32 por lo que son de un valor teórico de primer orden. A la vez, la teoría es comprendida como momento teórico de la praxis; ${ }^{33}$ es, pues, parte de dicha praxis. Por ello, para la teoría crítica, tal y como sostiene Mardones, "la praxis es el elemento definidor de qué sea lógico o no. Más, la praxis es el lugar donde se prueba y comprueba la veracidad de toda crítica ideológica, la razón que lleva consigo la Teoría Crítica." ${ }^{34}$

Es bajo esta misma comprensión, al constatar que la facticidad es consustancial al pensamiento, que Ignacio Ellacuría, ${ }^{35}$ reflexionando sobre la labor de la filosofía en los procesos de liberación de América Latina, la entiende como momento de la praxis emancipadora, recibiendo de ella su determinación última. ${ }^{36}$ La filosofía, según es entendida por Ellacuría y de la forma en que fue desarrollada por él, se concibe a partir de la implicación en una praxis histórica de liberación, en la búsqueda por comprender y transformar la realidad. Ahora bien, ahondando en la función específica de la tarea teórica, dirá que ésta tampoco puede ser reducida a mero reflejo de la praxis de liberación:

${ }^{29}$ SANTOS, Boaventura. La caída del Angelus Novus: Ensayos para una nueva teoría social. 1. ed. Bogotá: Ilsa, 2003. p. 119. (Colección En Clave de Sur).

${ }^{30}$ Cfr. SOlóRZANO, Norman. Crítica de la Imaginación Jurídica. Una mirada desde la epistemología y la historia al derecho moderno y su ciencia. San Luis de Potosí: Universidad Autónoma de San Luis de Potosí, 2007. p. 53.

${ }^{31}$ GALLARDO, Helio, Teoría crítica y derechos humanos. Una lectura latinoamericana. In: FUNDACIÓN JUAN VIVES SURIA; DEFENSORIA DEL PUEBLO VENEZUELA. Los derechos humanos desde el enfoque crítico. Caracas: Fundación Juan Vives Suria, 2011. p. 72.

32 MARDONES, José María, Razón comunicativa y teoría crítica. La fundamentación normativa de la teoría crítica de la sociedad. Bilbao: Servicio Editorial de la Universidad del País Vasco, 1985. p. 30.

${ }^{33}$ Cfr. Ibidem, p. 32

${ }^{34}$ MARDONES, José María, "La ideología según la teoría crítica de la escuela de Frankfurt. (M. Horkheimer, T. W. Adorno y J. Habermas)”. In: Pensamiento, Madrid, v. 36, n. 11, p. 393, 1980.

${ }^{35}$ ROMERO CUEVAS, José, Ellacuría: una teoría crítica desde América Latina, p. 9. Disponible en: http://uah.academia.edu/Jos\%C3\%A9ManuelRomeroCuevas/Papers/1646652/I._Ellacuria_una_teoria_critica_desde_America_Latina. Acceso en: 5 sept. 2012).

${ }^{36} \mathrm{Cfr}$. ELLACURÍA, Ignacio. Relación teoría y praxis en la teología de la liberación. In: Escritos Teológicos, San Salvador: UCA Editores, Tomo I, p. 235, 2000. 
No todo momento de la praxis es consciente ni todo momento de la praxis tiene el mismo grado de conciencia. Cuando ese grado de conciencia se separa reflejamente de la praxis y se constituye en discernir de ella, en juicio y crisis de ella, se puede empezar a hablar de teoría, la cual se puede ir constituyendo en momento relativamente autonómico más allá de ser reflejo acompañante de la praxis. ${ }^{37}$

No se trata, por tanto, de desconocer el papel específico y la importancia de la teoría que intenta comprender, analizar, visibilizar posibilidades alternativas, articular propuestas en curso y abrir horizontes de análisis, pues una praxis emancipadora requiere el análisis de las estructuras que subyacen a los procesos de dominación, ${ }^{38}$ que permita identificar virtualidades presentes en ellas que, al no ser evidentes a primera vista, "exigen ser imaginadas y pensadas. Esto quiere decir que la estructura no es un dato, sino tendencias y procesos conflictivos que exigen ser imaginados por una voluntad y pensados mediante una teoría." ${ }^{39}$

En todo caso, es manifiesta la dimensión política del pensar para la filosofía de la liberación, como lo es para todo pensamiento crítico. ${ }^{40}$ Las teorías, todas las teorías, lo son de la práctica; más aún, de una práctica social; siendo así, lo político les es constitutivo en la medida en que a ellas subyace la pretensión de ofrecer un modo de organizar la realidad, a través del discurso y del pensamiento. ${ }^{41}$ No asumir conscientemente esta dimensión política afectaría al propio trabajo del intelectual, limitando su capacidad para entender la realidad y para comunicar adecuadamente las posiciones que toma. ${ }^{42}$ Por ello, será necesario atender al papel específico que se supone cumplen los teóricos; de ello nos ocuparemos en el próximo apartado.

\section{LA LABOR DE LOS TEÓRICOS}

Visto lo que se entiende por teoría desde la perspectiva del pensamiento crítico, revisaremos ahora la labor específica que se supone han de aportar los intelectuales, intentando identificar sus rasgos característicos.

Desde la perspectiva a la que apostamos, quienes se dedican de manera particular a la tarea de teorizar, habrán de tener cuidado de desmarcarse del papel al que inercialmente pueden verse inclinados dado el status que ocupa el "trabajo intelectual", y concretamente los propios intelectuales, en nuestras sociedades. Así, los teóricos necesitan una permanente atención sobre sí mismos para no incurrir en posturas propias de la lógica "iluminista", como si fuesen los que "crean" o "saben" las respuestas a las más diversas problemáticas sociales que nos aquejan; sin duda, éstos hombres y mujeres tienen un aporte específico que realizar desde el ejercicio reflexivo; pero el mismo, no se orienta a "enseñar" lo que debe hacerse sino a posibilitar los espacios y a ofrecer su palabra de forma tal que cada quien, individual y colectivamente, tenga las condiciones necesarias para poder formular proyectos vitales y construirlos.

En ese sentido, los intelectuales, con su aporte crítico, desde el rechazo al pensamiento y al cierre de alternativas, convocando y estimulando una indignación consciente, ${ }^{43}$ contribuyen a los procesos de organización y movilización, favoreciendo así la conciencia de poder por parte de los sectores más vulnerables. ${ }^{44}$ Por eso, recordando el aporte hecho por Rosa Luxemburgo a los procesos de lucha, Herrera Flores dirá que es preciso lo siguiente:

${ }^{37}$ ELLACURÍA, Ignacio. Función liberadora de la filosofía. In: ELLACURÍA, Ignacio. Veinte años de historia en El Salvador (1969-1989). Escritos Políticos, San Salvador: UCA Editores, Tomo I, p. 63, 1993.

${ }^{38}$ Cfr. HINKELAMMERT, Franz. La maldición que pesa sobre la ley. Las raíces del pensamiento crítico en Paulo de Tarso. San José de Costa Rica: DEI, 2010. p. 265.

${ }^{39}$ GALLARDO, Helio. Sobre las generaciones de derechos humanos. p. 14. Disponible en: http://heliogallardo-americalatina.info/index. php?option=com_content\&task=view\&id =179\&ltemid=1. Acceso en: 15 marzo 2013.

${ }^{40}$ Cfr. ROSILLO, Alejandro. Derechos Humanos desde el pensamiento latinoamericano de liberación. 2011. Tesis doctoral presentada en el Instituto de Derechos Humanos Bartolomé de las Casas. Doctorado en Estudios Avanzados en Derechos Humanos. Getafe, jun. 2011. p. 377.

${ }^{41}$ Cfr. GRUNER, Eduardo. "Los avatares del pensar crítico hoy por hoy". In: Cuaderno de Pensamiento Crítico Latinoamericano, Clacso, n. 44, a. 4,15 oct. 2011.

${ }^{42}$ Cfr. HINKELAMMERT, Fran. Percepciones y marcos categoriales de lo político. Entrevista de Germán Gutierrez. In: DUQUE, José; GUTIÉRREZ, Germán (ed.). Itinerarios de la razón crítica. Homenaje a Franz Hinkelammert en sus 70 años. San José, Costa Rica: DEI, 2001. p. 185.

${ }^{43}$ Cfr. HERRERA FLORES, Joaquín, De la rueda y el freno. "El camino hacia la democracia en Georg Lukacs y Rosa Luxemburg." In: Crítica Jurídica. Revista Latinoamericana de Política, Filosofía y Derecho, Facultades do Brasil, n. 18, p. 259-281, 2001.

${ }^{44}$ Cfr. GALLARDO, Helio. Derechos Humanos. p. 7. Disponible en: http://heliogallardo-americalatina.info/index.php?option=com_content\&task=view\&id=144\&Itemid=9. Acceso en: 10 oct. 2012. 
Armarnos con conceptos y formas de praxis que tiendan a conquistar la mayor cantidad posible de "espacios sociales" de democracia; espacios donde los grupos y los individuos encuentren posibilidades de formación y de toma de conciencia necesarias para combatir la totalidad de un sistema caracterizado por la reificación, el formalismo y la fragmentación. ${ }^{45}$

Es necesario, pues, el esfuerzo teórico que permita desentrañar los intereses ocultos tras los discursos y los proyectos socioeconómicos, visibilizar la violencia que subyace a la hegemonía jurídica y política. ${ }^{46}$ Para ello, el intelectual podrá echar mano "de lo nuevo y de lo viejo", sabiendo reapropiarse de la tradición, o apoyándose en trayectos poco explorados de la misma que permitan subvertir y transformar lo que reproduce las asimetrías productoras de subalternización en nuestro mundo. ${ }^{47}$ "Este mirar a donde otros no han mirado convierte al científico social en un arqueólogo subversivo (sub vertere, la versión desde abajo)." ${ }^{48}$

Esta tarea, insistimos, no se lleva a cabo como fruto de cierto ensimismamiento especulativo, sino a partir del proceso de diálogo permanente que los intelectuales han de sostener con las distintos procesos de lucha social que se desarrollan, pues desde el enfoque de la teoría crítica, la verdad sólo es tal en la medida en que sirve para enfrentar los retos que plantean las luchas dirigidas a construir un mundo más justo e igualitario. Es en diálogo con quienes llevan adelante las distintas prácticas sociales que intentan transformar la realidad donde la labor del intelectual haya su razón de ser, poniendo en relación teoría y práctica. Por eso, marcando distancia frente a la autocomprensión que acompañó durante muchos años a los teóricos de izquierda, Boaventura de Sousa Santos entiende que en los actuales procesos de lucha por la transformación social y política son necesarias teorías de retaguardia. Estas teorías las define en los siguientes términos:

Son trabajos teóricos que acompañan muy de cerca la labor transformadora de los movimientos sociales, cuestionándola, comparándola sincrónica y diacrónicamente, ampliando simbólicamente su dimensión mediante articulaciones, traducciones, alianzas con otros movimientos. Es más un trabajo de artesanía y menos un trabajo de arquitectura. Más un trabajo de testigo implicado y menos de liderazgo clarividente. Aproximaciones a lo que es nuevo para unos y muy viejo para otros. ${ }^{49}$

Se trata, por tanto, de un hacer teórico que no pretende sustituir los saberes y experiencias de los distintos actores sociales que apuestan por la emancipación social, ni asumiéndose sus artífices como portadores de un saber superior que habrá de apuntar los caminos a seguir. ${ }^{50}$

No se plantea una creación de teoría ex nihilo, sino de aportar en un diálogo de saberes a quienes desde la reflexión de su praxis histórica van dotando permanente de sentido el quehacer por la transformación social. ${ }^{51}$ Se contribuye, pues, a una interpretación de la realidad desde las propias prácticas sociales que en medio de dificultades y contradicciones, y con niveles distintos de organización, articulación y movilización, van constituyendo una alternativa al secuestro de discurso y realidad que se viene operando desde el saber hegemónico. De esta manera, apostando por formas alternativas de racionalidad y conocimiento, ${ }^{52}$ se contribuye a identificar que lo dado no agota el campo de posibilidades; que existen prácticas sociales alternativas; que "otro mundo es posible". ${ }^{53}$ Así, desde el diálogo y acompañamiento, intentando articular y traducir las

\footnotetext{
$\overline{45}$ HERRERA FLORES, Joaquín. "De la rueda y el freno. El camino hacia la democracia en Georg Lukacs y Rosa Luxemburg." In: Crítica Jurídica. Revista Latinoamericana de Política, Filosofía y Derecho, Facultades do Brasil, n. 18, p. 16, 2001.

${ }^{46}$ HERRERA FLORES, Joaquín. Prólogo. In: MEDICCl, Alejandro. El malestar en la cultura jurídica. Buenos Aires: Editorial de la Universidad Nacional de La Plata, 2011. p. 16.

${ }^{47}$ Cfr. HERRERA FLORES, Joaquín. "¿Crisis de la ideología o ideología de la crisis? Respuestas neoconservadoras." In: Crítica Jurídica. Revista Latinoamericana de Política, Filosofía y Derecho, Instituto de Investigaciones Jurídicas, Universidad nacional Autónoma de México, n. 13, p. 141, 1993.

48 MONEDERO, Juan Carlos. Estudio introductorio. Conciencia de frontera: la teoría crítica posmoderna de Boaventura de Sousa Santos. p. 54. Disponible en: . Acceso en: 1o oct. 2012.

49 SANTOS, Boaventura. Refundación del Estado en América Latina. Perspectivas desde una epistemología del Sur. Buenos Aires: Antropofagia, 2010. p. 23.

${ }^{50}$ Cfr. NUNES, João. "Transição paradigmática, pós-modernismo crítico e teoria social”. In: Oficina do CES, Coimbra: CES-FEUC, n. 81, p. 18, 1996.

${ }^{51}$ Cfr. GALLARDO, Helio. Derechos humanos como movimiento social. Colombia: Ediciones Desde Abajo, 2006. p. 17-18.

${ }^{52}$ Cfr. SANTOS, Boaventura. Conocer desde el Sur. Para una cultura política emancipatoria. Buenos Aires: Clacso, 2008. p. 81.

${ }^{53}$ Cfr. SANTOS, Boaventura. Crítica de la razón indolente. Contra el desperdicio de la experiencia. Bilbao: Desclée de Brouwer, 2003. p. 391, 393.
} 
distintas prácticas y saberes, recuperando la historia marginada y la reflexión despreciada, la teoría funcionaría, en palabras de Boaventura de Sousa Santos, como conciencia cartográfica de los caminos que van siendo recorridos por las distintas luchas políticas, sociales y culturales; luchas con las que mantiene una relación de influencia recíproca. ${ }^{54}$

Esta nueva forma de entender el papel de quien se propone realizar la tarea teorizadora (pensamos particularmente en el mundo académico), exige dejar atrás la auto-referencia como sujetos privilegiados productores del saber, y asumir la demanda de entrar en un diálogo de saberes no jerárquico con esos otros a quienes hasta ahora se ha tratado como meros objetos de conocimiento; en este desafiante camino, la experiencia de la pedagogía popular latinoamericana tiene mucho que aportar. ${ }^{55}$

Si pensamos específicamente en el campo de los derechos humanos, es necesario afirmar de manera enfática, contra ciertas teorías idealistas, que los mismos no son creaciones de intelectuales visionarios que posteriormente logran ser aterrizadas por los movimientos populares. Frente a esta concepción "platonizante" de la lucha por los derechos, es preciso reivindicar el papel protagónico de los movimientos sociales, sus saberes y sus prácticas, y de las demandas que de ellos surgen. Como afirma Boaventura de Sousa Santos

Na sua heterogeneidade, os movimentos sociais testemunham a vitalidade de uma concepção emergente dos direitos humanos a nível mundial, uma concepção cada vez menos resignada com a mera promulgação dos direitos humanos, e cada vez mais atenta às práticas quotidianas em que se satisfazem efetivamente as necessidades básicas, não só as necessidades materiais mas também as necessidades afetivas e expressivas, aquelas cuja satisfação nos confere um sentido e um lugar no mundo, num mundo de cidadãos. ${ }^{56}$

Por ello, asumiendo una perspectiva que valore los procesos sociales, es necesario tomar las luchas históricas por los derechos como eje epistémico, contribuyendo así al empoderamiento de los diversos actores que tienen en común el horizonte de la emancipación social. ${ }^{57}$

\section{REFERENCIAS}

ADORNO, Teodor. Dialéctica negativa. Madrid: Akal, 2005.

CORTINA, Adela. La Escuela de Fráncfort. Crítica y Utopía. Madrid: Síntesis, 2008.

COX, Robert. Theory Talk, n. 37. Disponível em: http://www.theory-talks.org/2010/03/theory-talk-37.html). Acceso en: 10 oct. 2012.

DUSSEL, Enrique. Ética de la Liberación en la Edad de la Globalización y de la Exclusión. Madrid: Trotta, 2006.

DUSSEL, Enrique. Política de la liberación. Historia Mundial y Crítica. Madrid: Trotta, 2007.

ELLACURÍA, Ignacio. Función liberadora de la filosofía. In: ELLACURÍA, Ignacio. Veinte años de historia en El Salvador (19691989). Escritos Políticos, San Salvador: UCA Editores, Tomo I, 1993.

ELLACURÍA, Ignacio. Relación teoría y praxis en la teología de la liberación. In: Escritos Teológicos, San Salvador: UCA Editores, Tomo I, 2000.

ELLACURÍA, Ignacio, Historización de los derechos humanos desde los pueblos oprimidos y las mayorías populares. In: Escritos Filosóficos, San Salvador, UCA Editores, Tomo III, 2001.

ETXEBERRÍA, Javier. Prólogo. In: ASIER, Martínez de Bringas. Exclusión y victimización. El grito de los derechos humanos en la globalización. Bilbao: Alberdania, 2004. p. 13.

GALLARDO, Helio. Derechos humanos como movimiento social. Colombia: Ediciones Desde Abajo, 2006.

GALLARDO, Helio. Derechos Humanos. Disponível em: http://heliogallardo-americalatina.info/index.php?option=com_content\&task=view\&id=144\&Itemid=9. Acceso en: 10 oct. 2012.

GALLARDO, Helio. Siglo XXI. Producir un mundo. Toronto, Canadá: Editora Harlequin, 2006.

\footnotetext{
${ }^{54}$ Cfr. SANTOS, Boaventura, Porque é tão difícil construir uma teoria crítica? In: Revista Crítica de Ciencias Sociales, n. 54, p. 214-215, jun. 1999.

${ }^{55}$ LANDER, Edgardo. ¿Reinventar el socialismo? In: Alternativas. Revista de análisis y reflexión teológica, Managua: Editorial Lascasiana, a. 19, n. 43, p. 42, enero/jun. 2012.

${ }^{56}$ SANTOS, Boaventura. Os direitos humanos na Pós-modernidades. In: Oficina do CES, Coimbra, n. 10, p. 12-13, jun. 1989.

${ }^{57}$ Cfr. GALLARDO, Helio. Teoría Crítica: Matriz y posibilidad de derechos humanos. Murcia: Gráficas Francisco Gómez, 2007. p. 312.
} 
GALLARDO, Helio. Sobre las generaciones de derechos humanos. Disponível em: ttp://heliogallardoamericalatina.info/index. php?option=com_content\&task=view\&id=179\&ltemid=1. Acceso en: 15 marzo 2013.

GALLARDO, Helio. Teoría crítica y derechos humanos. Una lectura latinoamericana. In: FUNDACIÓN JUAN VIVES SURIA; DEFENSORIA DEL PUEBLO VENEZUELA. Los derechos humanos desde el enfoque crítico. Caracas: Fundación Juan Vives Suria, 2011.

GALLARDO, Helio. Teoría Crítica: Matriz y posibilidad de derechos humanos. Murcia: Gráficas Francisco Gómez, 2007. p. 312. GRUNER, Eduardo. "Los avatares del pensar crítico hoy por hoy". In: Cuaderno de Pensamiento Crítico Latinoamericano, Clacso, n. 44, a. 4, 15 oct. 2011.

GUILLÉN, Maryluz. “Concepción hegemónica de los derechos humanos: la lucha de los Yukpas por su tierra”. In: Diálogo de Saberes, n. 4. Disponível em: http://dialogosaberes.ubv.edu.ve/index.php?option=com_content\&view=article\&id=158:concepcion-hegemonica-de-los-derechos-humanos-la-lucha-de-los-yukpas-por-su-tierra\&catid= 19: sumario-revista-no-4\&Itemid=13. Acceso en: 19 sept. 2012.

HERRERA FLORES, Joaquín. Prólogo al libro de Alejandro Medicci El malestar en la cultura jurídica. Buenos Aires: Editorial de la Universidad Nacional de La Plata, 2011.

HERRERA FLORES, Joaquín. “¿Crisis de la ideología o ideología de la crisis? Respuestas neoconservadoras”. In: Crítica Jurídica. Revista Latinoamericana de Política, Filosofía y Derecho, Instituto de Investigaciones Jurídicas, Universidad nacional Autónoma de México, n. 13, 1993.

HERRERA FLORES, Joaquín. "De la rueda y el freno. El camino hacia la democracia en Georg Lukács y Rosa Luxemburg". In: Crítica Jurídica. Revista Latinoamericana de Política, Filosofía y Derecho, Facultades do Brasil, n. 18, 2001.

HINKELAMMERT, Franz. Claves de un pensamiento crítico. Entrevista a Franz Hinkelammert por Henry Mora. In: HERRERA FLORES, Joaquín (ed.). El vuelo de Anteo. Derechos Humanos y Crítica de la razón Liberal. Bilbao: Desclée de Brouwer, 2000.

HINKELAMMERT, Franz. La maldición que pesa sobre la ley. Las raíces del pensamiento crítico en Paulo de Tarso. San José de Costa Rica: DEI, 2010.

HINKELAMMERT, Franz. Percepciones y marcos categoriales de lo político. Entrevista de Germán Gutierrez. In: DUQUE, José; GUTIÉRREZ, Germán (ed.). Itinerarios de la razón crítica. Homenaje a Franz Hinkelammert en sus 70 años. San José, Costa Rica: $\mathrm{DEI}, 2001$.

HORKHEIMER, Max. Teoría tradicional y teoría crítica. In: Teoría Crítica. Buenos Aires: Amorrortu, 1974.

LANDER, Edgardo. “¿Reinventar el socialismo?” In: Alternativas. Revista de análisis y reflexión teológica, Managua: Editorial Lascasiana, a. 19, n. 43, enero/jun. 2012.

MARDONES, José María. "La ideología según la teoría crítica de la escuela de Frankfurt. (M. Horkheimer, T. W. Adorno y J. Habermas)". In: Pensamiento, Madrid, v. 36, n. 144, 1980.

MARDONES, José María. Razón comunicativa y teoría crítica. La fundamentación normativa de la teoría crítica de la sociedad. Bilbao: Servicio Editorial de la Universidad del País Vasco, 1985.

MARTíNEZ de Bringas, Asier. Exclusión y victimización. El grito de los derechos humanos en la globalización. Bilbao: Alberdania, 2004.

MEDICCI, Alejandro. "El arraigo de Anteo: las lecciones políticas de Joaquín Herrera Flores". In: REDHES, San Luis Potosí: Universidad Autónoma San Luis Potosí, n. 4, jul./dic. 2010.

MONEDERO, Juan Carlos. Estudio introductorio. Conciencia de frontera: la teoría crítica posmoderna de Boaventura de Sousa Santos. Disponível em: http://www. boaventuradesousasantos.pt/documentos/Introduccionversionfinal-Juan\%20Carlos\%20 Mone dero.pdf. Acceso en: 10 oct. 2012.

NUNES, João. "Transição paradigmática, pós-modernismo crítico e teoria social”. In: Oficina do CES, Coimbra: CES; FEUC, n. 81, 1996.

Romero Cuevas, José. “Ellacuría: una teoría crítica desde América Latina”. In: Revista Internacional de Filosofía Política, Madrid: UAM-Uned, n. 32, p. 7, 2008.

ROSILLO, Alejandro. Fundamentación de los derechos humanos desde la Filosofía de la liberación. [201-?]. Mimeo.

ROSILLO, Alejandro. Derechos Humanos desde el pensamiento latinoamericano de liberación. 2011. Tesis doctoral presentada en el Instituto de Derechos Humanos Bartolomé de las Casas. Doctorado en Estudios Avanzados en Derechos Humanos. Getafe, jun. 2011.

SÁNCHEZ RUBIO, David. Filosofía, derecho y liberación en América Latina. Bilbao: Desclée de Brouwer, 1999.

SANTOS, Boaventura. La globalización del derecho. Los nuevos caminos de la regulación y la emancipación. Bogotá: Instituto Latinoamericano de Servicios Legales Alternativos - Ilsa, 1991.

SANTOS, Boaventura. “Porque é tão difícil construir uma teoria crítica?” In: Revista Crítica de Ciencias Sociales, n. 54, jun. 1999.

SANTOS, Boaventura. Crítica de la razón indolente. Contra el desperdicio de la experiencia. Bilbao: Desclée de Brouwer, 2003. 
SANTOS, Boaventura. La caída del Angelus Novus: Ensayos para una nueva teoría social. 1. ed. Bogotá: Ilsa, 2003. (Colección En Clave de Sur).

SANTOS, Boaventura. Conocer desde el Sur. Para una cultura política emancipatoria. Buenos Aires: Clacso, 2008.

SANTOS, Boaventura. Refundación del Estado en América Latina. Perspectivas desde una epistemología del Sur. Buenos Aires: Antropofagia, 2010.

SENENT DE FRUTOS, Juan. Notas sobre una Teoría Crítica de los Derechos Humanos. In: Anuario Iberoamericano de derechos humanos 2001-2002. Río de Janeiro, 2002.

SOLÓRZANO, Norman. Crítica de la Imaginación Jurídica. Una mirada desde la epistemología y la historia al derecho moderno y su ciencia. San Luis de Potosí: Universidad Autónoma de San Luis de Potosí, 2007.

ZEMELMAN, Hugo. Debate sobre la situación actual de las ciencias sociales. Disponível em: http://www.archivochile.com/ Ideas_Autores/zemelmanh/zemelman0007.pdf. Acceso en: 19 sept. 2012. 